Discourse and Identity in a Corpus of Lesbian Erotica

Liz Morrish (Nottingham Trent University, UK) and Helen Sauntson

(University of Birmingham, UK) 


\title{
Discourse and Identity in a Corpus of Lesbian Erotica
}

\section{(Liz Morrish, Nottingham Trent University, UK and Helen Sauntson, University of Birmingham, UK)}

\begin{abstract}
This article uses corpus linguistic methodologies to explore representations of lesbian desires and identities in a corpus of lesbian erotica from the 1980s and 1990s. We provide a critical examination of the ways in which 'lesbian gender', power and desire are represented, (re-)produced and enacted, often in ways that challenge hegemonic discourses of gender and sexuality. By examining word frequencies and collocations, we critically analyse some of the themes, processes and patterns of representation in the texts. Although rooted in linguistics, we hope this article provides an accessible, interdisciplinary and timely contribution towards developing understandings of discursive practices surrounding gender and sexuality.
\end{abstract}

Shortened title: Discourse and identity in lesbian erotica

\section{Keywords}

Lesbian sexuality

Gender

Female masculinity

Lesbian erotica

Corpus linguistics 


\section{Biographies}

\section{Liz Morrish}

Liz Morrish is Principal Lecturer in Linguistics at Nottingham Trent University, UK. Earlier in her career she studied experimental phonetics and disordered speech, leading to the award of a $\mathrm{PhD}$ from Leeds University. Her current primary research and teaching interests are language and sexual identity, and language and gender. She is the author (with Helen Sauntson) of New Perspectives on Language and Sexual Identity (Palgrave, 2007). Liz is on the organising committee of the Lavender Languages and Linguistics conferences held annually in Washington DC and the Queering Paradigms II conference to be held in Brisbane, Australia in 2010.

\section{Helen Sauntson}

Helen Sauntson is a lecturer in English Language and Linguistics at the University of Birmingham, UK. She holds a PhD from the University of Birmingham. Her main research areas are classroom discourse analysis and language, gender and sexuality. She is the author (with Liz Morrish) of New Perspectives on Language and Sexual Identity (Palgrave, 2007). She is the editor (with Sakis Kyratzis) of Language, Sexualities and Desires: Cross-Cultural Perspectives (Palgrave, 2007) and Gender and Language Research Methodologies (co-edited with Kate Harrington, Lia Litosseliti and Jane Sunderland) (Palgrave, 2008). 


\section{Discourse and Identity in a Corpus of Lesbian Erotica}

\section{Introduction}

In this article we employ some methods of corpus linguistics to investigate how lesbian desires and identities are represented in a small corpus of lesbian erotica from the late 1980s and early 1990s. Corpus linguistics is a technique which involves collecting together electronic collections of texts and submitting them to analysis by specially designed software which can search for otherwise unobservable patterns in language use. Techniques of analysis include word frequency lists and collocations - semantic and grammatical environments of particular words. We examine how lesbian genders and desires, particularly female masculinity and power, are reproduced and enacted in the texts in ways that challenge hegemonic discourses of gender and sexuality. We also discuss how these discourses circulate to create possibilities for identity formation within lesbian communities. Our aim is to employ some of the objectives of critical discourse analysis by setting out to uncover ideologies in the texts. Hunston (2002: 123) summarises the potential benefits that corpus linguistics offers critical discourse analysis:

Many of the arguments that critical linguists use depend upon assumptions about the influence upon people and on society of language whose meaning is covert. It seems apparent, then, that corpora are a very useful tool for the critical linguist, because they identify repetitions, and can be used to identify implicit meaning. 
In order to identify these implicit meanings, we use the specific corpus techniques of examining word frequencies and collocations. By using the concordancing and other functions of Wordsmith Tools (Scott, 1996), we analyse some of the key themes, processes and patterns of representation in these texts. Stubbs (1996) argues that the semantic patternings revealed by these techniques can contribute to the production of certain discourses in the corpus and he defines a discourse as 'recurrent phrases and conventional ways of talking, which circulate in the social world, and which form a constellation of repeated meanings.' (Stubbs, 1996: 158) Our analysis simultaneously investigates two related discourses. Firstly, we examine what corpus-based analysis reveals about discourses of lesbian desires and sexual practices in our texts. Secondly, we explore how and what kinds of lesbian identities are discursively constructed, particularly in terms of gender and female masculinity. These two discourses are related but, as we will discuss, often in quite complex ways. In a social, political and academic context in which lesbian sexual practices and identities are still relatively marginalised, this study provides some illumination of the social dynamics of lesbian sexuality as they are linguistically realised in our corpus of erotic texts. It is hoped that the findings presented in this article will provide a contribution to our developing understanding of lesbian sexuality and some of its various social, political and cultural formations in erotic textual practices.

\section{Previous studies: Setting the context}

Although ours is the first study to apply corpus linguistic methods to lesbian erotic texts, two studies (Baker, 2004a; Bolton, 1995) on the analysis of gay male erotica have been useful in informing our research in terms of methodology and analysis. Bolton's 
study looks at the frequency of lexical items in certain semantic and grammatical categories in order to establish the 'erotic salience' (1995: 184) of these in his gay male corpus. His analysis is very revealing: the most frequent body parts are penis, anus, hands and mouth. The most frequent actions for gay men are throbbing, straining, pulsing, exploding, invading. In terms of aesthetics, the lexical analysis shows that gay men are often described as perfect, well-shaped, fabulous, beautiful, nice and handsome. Frequent terms for arousal are hard, stiff, swelling, erected, rock hard, swollen and rigid. Bolton argues this tells us that gay male sex is represented in the texts as hydraulic, cock-and-ass focussed, orgasm centered, with plenty of ballistic verbs and machine metaphors. There is a sculptor's aesthetic of bodies and a prizing of priapic hardness. This study shows that basic information about lexical frequency can begin to reveal themes of desire and identity in texts. For this reason, we employ this same analytic method as part of our own study.

Our 60,000 word corpus consists of a collection of lesbian erotica texts ( 40 short stories), produced in the USA between 1989-1994. The stories are taken from two lesbian magazines - On Our Backs and Bad Attitude. We selected stories which were at least 1000 words long and which focus largely on one-on-one sexual encounters. These may be narrated from the point of view of either the butch (or dominating) party, or of one who is seduced or dominated.

We have assumed the authenticity of lesbian authorship on the basis of, firstly, the sub-cultural production and distribution values of these publications, and secondly, consumption - the fact that they engage a lesbian audience. On Our Backs first appeared in 1984. The website (http://www.onourbacksmag.com/history.html) records that the first editors launched it as a response to the anti-pornography agenda (Dworkin, 1987; 
Mackinnon, 1993) of most lesbian and feminist organizations and media at the time.

Distribution of both publications in the early days was solely in gay and lesbian bookstores in major cities. In recent years, they have become more widely obtainable in national and international chains such as Borders, and Barnes and Noble and online.

On Our Backs announces itself as 'for the adventurous lesbian', but that designation relates solely to the field of sexual practice. Bad Attitude advertises 'lesbian erotic fiction' and both publications accompany their stories with photographs and drawings. Many of the artistic representations and photographs show soft sadomasochistic (henceforth $\mathrm{S} / \mathrm{M}$ ) practices such as piercing, tit-clamping, bondage and domination.

These are texts which emerged in a cultural context where their very existence was a matter of challenge from disparate quarters. In the 1990s there was a wider debate over the public availability and display of sexually explicit material, after the Meese Commission had pronounced on 'pornography' in 1986 (Attorney General's Commission on Pornography, 1986). The pro-sex platform espoused by the magazines can be seen as a political stance emerging in the face of all the anti-pornography campaigns of the 1980s. Bright (1998) suggests this was an attempt to emulate gay male culture with its pornography, bars and sex clubs, and it seemed to appeal to a generation of lesbians enlightened by notions of gender role fluidity, female masculinity and sexual empowerment. But the magazines which provided material for our corpus appear to offer new symbolic territory for lesbians to explore. Lamos (1994) interrogates the way in which On Our Backs generates a new discursive formation for the representation of the postmodern lesbian. For groups of lesbians at the turn of the decade, Bad Attitude and On Our Backs represented a refreshing acknowledgment that lesbians did have sex, 
lots of it, with different partners and in different ways. Sex could be a game and a form of self-expression in a world where women's access to sexual gratification had been restricted, stigmatised and subject to repression. One notable figure among the 'sexpositive' lesbian group of writers and consumers was Susie Bright. Bright's work $(1995 ; 1992 ; 1990)$ is not only a manifesto for the exploration of a lesbian, feminist erotic, but also a critique of what inevitably came to be seen as the sex-negative feminists, or retrofems (1995: 95). She writes, 'When feminists and writers first started discussing the future of women's erotica, there was a call for a new woman-centred language, a modern vocabulary to discuss women's sexual feelings. As an editor, I find that the language is there -- at the tips of our tongues. What is harder than imagining the words is saying them out loud....What's really missing in our erotic language are descriptions of women's arousal' (1995: 39). Such descriptions, we argue, are present in the texts which constitute our corpus, and are key to understanding lesbian identities and desires.

Other previous academic work has explored the suppression and invisibility of lesbian desire and identity in heteronormative contexts. For lesbians to talk about sexual desire and sexual practice is to search for a discourse with which to make the lesbian body and sexual experience intelligible to lesbians and not simply framed within socially dominant heterosexual experience. Frye (1990: 311) finds that the lesbian sexual experience is 'inarticulate and confined to the pre-linguistic and pre-cognitive realms of consciousness', such as duration, postures, positions, dynamics, connections, inhibitions, trajectories of pleasure. What is missing is a discourse that records the vitality of sexual desire, which Zita calls a 'lesbian authorship of 'self' (1990: 341). In 
discovering a discourse of desire in our corpus, what emerges are different identificatory possibilities, not merely a description of lesbian sexual practice.

At the level of lexis, Morrish's (1992) study found a paucity of words for expressing lesbian sexual desire. This was a questionnaire-based study and it verified that terms for sexual practice and the body inhabit a rather arid area of lexis for lesbians. The words which lesbians did use for describing sexual practice seemed to have been culled from the language of heterosexual or even gay male culture (e.g. screwing, dicking, jamming, fisting), and all suggested that lesbians view themselves as gay males manqué. The language of the body proved even more barren, because, unlike gay and straight men, women do not uniquely name their genitals or sensitive parts of the body. The scarcity of terminology revealed in this study stands in contrast to the data of gay men which features over-lexicalisation of the erogenous zones (Baker, 2004a; 2204b; 2004c; Bolton, 1995; Heywood, 1997; Jacobs, 2000). Morrish's study revealed that the labia, clitoris and vagina had no woman-originated nicknames, a finding which invites a comparison with the number of names for 'penis' - some fifty different terms (Bolton, 1995). Nor were the different sexual organs linguistically differentiated since they were most often glossed as 'cunt'. Are we then seeing the kind of 'mutedness' proposed by Spender (1980), when it comes to lesbians and the language of desire?

While issues of role, representation and sexual practice are our primary focus in this article, we have also sought to investigate what Butler (1993), borrowing from Lacan, has called the 'lesbian phallus'. While Butler's concept of the lesbian phallus predates Halberstam's work on female masculinity, the two currents of thought are clearly linked. Butler's starting point is a Lacanian notion of the phallus as signifier, which, moreover, belongs to the imaginary - the realm of the unconscious and fantasy. 
Following Saussure, if signifier and signified have only a conventional link, then there is no intrinsic connection between the signifier phallus, and the male penis: ' $[\mathrm{T}] \mathrm{o}$ the extent that the phallus symbolizes the penis, it is not that which it symbolizes. The more symbolization occurs, the less ontological connection there is between symbol and symbolized' (1993: 84). Of more interest, Butler argues, is how the phallus is constructed in lesbian sexuality, and the prospect of replacing a hegemonic imaginary with an alternative imaginary. Butler argues for an 'aggressive reterritorialization' (1993: 86) of the phallus so that the possibility arises that the phallus can be symbolized by an arm, a hand, a knee, a pelvic bone (1993: 88). It is this hypothesis of phallic displaceability (1993: 84) which opens the way for a representation of the lesbian phallus in both psychological and more concrete manifestations. Despite these theoretical elaborations, women have historically not been given the best of semantic platforms for articulating fantasy and desire.

\section{Lesbian identities}

'Butch' and 'femme', identity practices which are central to many of the stories included in our corpus, had been contested identities throughout the 1970s and 1980s. The terms refer to forms of social behaviour, including linguistic behaviour, which exploit and manipulate masculine and feminine gender codes and symbols (Rubin, 1992). Munt (1998) refers to butch and femme as forms of 'lesbian gender' and argue that they are semiotic practices which enable lesbians to, either temporarily or on a more permanent basis, engage in the construction and enactment of certain kinds of identities and/or desires. Butler (1990), Halberstam (1998) and Munt (1998) discuss butch and femme in terms of performativity - they are like a set of clothes which can be 
consciously put on for effect. However, they have noted, importantly, that femme and butch are also about experience, identity and subjectivity. Women who perform femme and butch often report that it is who they are, rather than simply something that they do. Femme and butch have been discussed by Munt as 'desire practices' and this is certainly evident in many of our texts. However, we argue that butch and femme do not always have to be based upon mutual attraction. Butches can desire other butches and femmes can desire other femmes (Jalas, 2005). Munt also notes that butch and femme are the two most public lesbian genders in Western societies, both as singular categories, and as a co-dependent or relational entities. She argues that femme and butch circulate around notions of womanhood with the butch being perceived and constructed by heteronormative discourse as a 'failed woman' and the femme as a 'hyper-woman'.

Butch-femme performances have often been regarded as a tool for the oppression of lesbian sexuality and it has been argued that the gender roles of butch and femme reinforce and perpetuate heteronormative stereotyping in terms of gender and sexuality (Ardill and O'Sullivan, 1990). However, in this article, following the work of Butler, Halberstam and others, we propose an alternative approach - through exposure and re-construction, butch-femme performances can function to present a radical critique of heteronormative gender discourses and ideologies. A common historical debate surrounding femme-butch has been the question of whether it is actually oppressive to lesbian sexuality through its privileging of heteronormative gender roles, or whether it is celebratory and liberating through its queer re-appropriation, and thus disruption, of those roles. Butler (1990) makes the important point that femme and butch do not constitute attempts to simply copy the roles of 'woman' and 'man' in heterosexual relationships, nor are they are straightforward imitations of 
heterosexuality. Parts of our analysis in this article explore how butch-femme discourses have the potential to disrupt dominant discourses of gender by analysing the performances of lesbian gender and desire in the erotic stories which make up our corpus.

As the desire and identity practices surrounding butchness seem to be particularly important in the stories, it is worth considering in more detail some theoretical work on the categories of butch, female masculinity and the notion of power. Halberstam (1998) argues that butchness is a lesbian form of female masculinity, but is not the only form of female masculinity. She argues for the liberation of masculinity from male embodiment, and for a critique and a wider understanding of what constitutes masculinity in a female context. Butchness is a lesbian gender identity because sexual desire for other women is as much a component of it as the operation of masculine gender codes. Halberstam proposes that butchness provides one means of enabling women to 'own' masculinity and make it their own, rather than it being held exclusively within the domain of men, and only enacted through male bodies. Moreover, butchness is a particularly threatening and subversive form of female masculinity because it is coupled with homosexual desire as is evident in our corpus.

In western societies, masculinity suggests power, although it is important to point out that masculinity does not automatically equate to power. It is rather the case that masculinity has certain cultural associations with power which, when unquestioned, are able to manifest themselves in everyday events and daily interactions, as Halberstam (1998: 2) argues: 
Masculinity in this society inevitably conjures up notions of power and legitimacy and privilege; it often symbolically refers to the power of the state and to uneven distributions of wealth.

When a butch lesbian performs masculinity, then, she is also performing the power that ideologically accompanies her masculinity. Interestingly though, the semantic resources of power are often deployed for erotic effect in the stories we have analysed, rather than for the purpose of the social oppression or denigration of the femme. Indeed, it is important to remember that butch and femme embody specific patterns of sexual practice and desire, as well as being subversive re-appropriations of masculinity and femininity. The relationship between gender and desire in relation to femme and butch is interesting and we will attempt to explore aspects of the relationship in our analysis.

\section{Corpus linguistics and the study of erotic texts}

We used corpus linguistic in our research primarily because it enables us to make observations about language use which go beyond intuition and allows the exploration of patterns of language use which are not observable to the human eye. It is acknowledged that the use of smaller and more specialised corpora can make useful contributions to understanding the language use of specific groups of people or the language patterns found particular text types (Kennedy, 1998). We argue that using a specialised corpus of texts written to represent lesbian desires and identities can help to reveal the specific linguistic practices systematically used to construct those kinds of desires and identities.

Despite the apparent benefits of using corpus linguistic methodology to further critical discourse and sociolinguistic inquiry, relatively few studies have been produced 
so far which do so, especially in the area of language, gender and sexuality. As outlined earlier, Baker (2004a) is probably the first to have systematically applied corpus methods to the study of language and sexuality. Interestingly, Baker argues that recent postmodern approaches to exploring the discursive construction of gender and sexuality may not immediately appear to lend themselves well to the quantitative and empirical approaches offered by corpus linguistics. But Baker goes on to question the split between qualitative and quantitative approaches in corpus research and argues that both forms of research can actually complement each other or perhaps that they are components of the same process. He argues that there is no legitimate reason why the quantitative empirical data obtained from corpus research could not be interpreted and explained qualitatively in terms of exploring how sexual identities are discursively constructed in a particular corpus.

In a similar way to Baker's study, the main methods we use here are word frequencies and collocation analysis. The corpus analysis presented here is word-based primarily because of the limited scope of the article. We have not sought to provide a detailed and exhaustive corpus analytical study in this article ${ }^{\mathrm{i}}$. Examining the frequencies of words in a corpus is a helpful way of making comparisons between them. McEnery and Wilson (1996: 82) define a word frequency count as 'the number of items (or tokens) within the text which belong to each classification (or type).' Word frequency lists can reveal information about the most commonly-occurring words in a corpus (which may, in turn, reveal information about particular themes or topics which predominate) as well as any words which may be 'marked' because of their frequency. The word frequencies we have analysed are presented as raw data - we have listed the actual number of occurrences of words rather than presenting them as a percentage or 
proportion of the whole corpus. We have eliminated the grammatical words from our frequency lists as the lexical words are of more importance in revealing prevailing themes and meanings.

In themselves, word frequency lists are fairly limited in the information they can give us about how meanings are created in the corpus. Thus, the next stage in our study was to carry out collocation analyses as well as some qualitative analyses of some of the concordance lines of the frequent words we identified. Baker et al (2006: 76) state that 'frequencies do not explain themselves: concordance-based analyses are therefore required in order to explain why certain words are more frequent than others.' Therefore, we have examined the semantic environments of some of the words in the frequency lists by looking closely at some of the concordance lines (and, in some cases, at wider stretches of text) in which they occur. This gives us information about how particular words are behaving and allows us to focus qualitatively on specific examples of word use. However, this kind of analysis can only be carried out on a few examples. Collocation analysis provides a more quantitative approach which can be used to pick up word associations and patterns in the whole corpus which the human eye cannot see.

Collocation analysis goes beyond simply looking at word frequencies to examining the semantic environment of particular words in a corpus. A collocation is a word which occurs within the neighbourhood of another word. Collocation analysis of frequent words can give us information about the connotational meanings of those words, and the ways in which particular words 'behave' in a corpus. Stubbs (1996: 172) explains that collocations 'show the associations and connotations [words] have, and therefore the assumptions which they embody.' Collocational analyses can illuminate 'meaningful associations' in the corpus as well as giving clues about the dominant 
phraseology of a word and enabling the analyst to obtain a profile of the semantic field/s of a word (Hunston, 2002). In our analysis, we have selected some of the most frequent lexical words and have carried out collocation analyses to explore the semantic environment of those words. Clearly it would not be possible to examine all of the most frequent words in this article, so we have selected some of those high-frequency lexical words which we believe will be of interest based on our knowledge of the genre and audience of the texts which comprise the corpus. This selection criteria is common practice in corpus linguistic research.

The combination of corpus techniques described above enable us to build up a profile of the semantic environment of the most frequent words in the corpus which, in turn, can be used to illuminate the themes, ideologies and semantic associations inscribed in the texts.

\section{Lexical frequency}

A word frequency list can begin to reveal information about the themes within the corpus. The frequent lexical words in our corpus are grouped into emergent semantic and word class categories in table 1 (numbers in brackets indicate the number of times each word or lemma occurs in the corpus - the higher the number the higher the frequency)

[Table 1 here]

The frequencies of these lexical items begin to reveal some emergent themes concerning sexual desire and identity in the corpus. They firstly reveal a sado-masochistic focus 
(e.g. leather, harness, cuffs, spanking), and the related issues of power, dominance and control are indicated (e.g. pain, power, control). A first reading of the word frequencies might indicate violence, but the frequent adverbs would seem to modify this assumption - these actions are often done gently and slowly as well as, at other times, roughly. In terms of sexual activity, there are a large number of verbs which do not encode vigorous physical activity: (e.g. feel; know; say; touch) but which instead encode a rather cerebral approach to the erotic. This suggests it is as important to represent physical and emotional contact in the stories as it is to represent sexual activity. Sex seems to encompass a mental dimension, with verbs of sensation and cognition occurring almost as much as verbs of action. In fact the most frequent highly sexual verbs fuck and come $e^{i t}$ appear only half-way down the total list of verbs. In terms of references to the body, the importance of hands is primary, and genitals is secondary, although cunt is the most lexicalized item. All of this starts to imply that different discourses of sexual practice can animate the lesbian eros in our corpus.

\section{Collocations of some frequent words and discourses of sexual practice and identity}

The next stage in our analysis is to consider the semantic environment of the most frequent lexical words in the corpus by examining some of their collocational patterns. Again, analysing the collocations of some frequent words is helpful for revealing dominant discourses of lesbian gender, sexual activity and practice.

We firstly examined the collocational patterns surrounding fuck* which is the most frequent verb of sexual activity. The way that fuck* behaves semantically is revealing in terms of the represented desire, power and agency of the narrator. 
[Table 2 here]

Fuck is not very often modified by adverbs, but on occasions we find: 'gently she began to fuck' (Table 2, line 15). Fuck materializes with fantasy scenes - it occurs a lot in quotations (Table 2, lines $5,6,8,18,20,22$ ), and so is something said or requested. Collocates which occur several times in the list are please, hard and harder, and terms of abuse whore, Mistress and slut (Table 2, lines 4, 5, 6, 12, 16). It is used fifty percent of the time as an intensifier, rather than a verb (e.g. it intensifies horny, wet, slut and whore). Again, the relative frequencies of these lexical items tell us that verbal abuse plays an important role in terms of creating erotic context in these specific texts.

The collocations of fuck* with adverbs, pronouns and serial verbs reveal that narrators are frequently active parties. When we examine the collocations of fuck we find her to the Right, and want to fuck occurs more frequently than want her to fuck, indicating that the narrator is also the one doing the fucking. When the object is you, this inevitably positions the object as 'femme' and receptive. This always constructs an erotic dynamic rather than actualising systems of gender oppression. We looked for the possibility of reciprocity exemplified by each other which has 23 occurrences. None of these co-occur with fuck; instead reciprocity is strongly associated with the more gentle activities of make love to, play with, kiss, caress and hold. In her study of patterns of reciprocity in heterosexual erotic texts, Manning (1997: 54) suggests that reciprocity correlates with certain other prepositions; in our corpus to has 1639 occurrences and with 532 occurrences. Manning found that to was used to encode male heterosexual activity, while with was used more frequently with reference to female heterosexual 
activity. She suggests that with is an indicator of cooperative patterns. Clearly, in our corpus, there is a predominance of agentive actors and perhaps acquiescent partners.

Despite this, butch power is often leavened by markers of consensuality and gentleness, and these are strongly indicated as erotic themes through other word frequencies and their collocational patterns. First of all, the language of affection is quite evident: honey (19 as term of affection), lovely (4 only as an adjective qualifying a body part), darling (1), dear (6 collocates with my), baby (26 collocates strongly with precious to the Left), sweetie (3), goddess (3 but as a name). Secondly, we also find that there is usually a slow onset of activity (high frequency of multi-verb begin to/ start to constructions), and a lot of begging takes place. The verb fuck collocates with please, began to, starting to and want to (Table 2, lines 6, 15, 22).

Even when there is whipping or spanking, it is often described as gentle or nice which appear as frequent collocates. There is no frenetic pace to the sexual activity in our corpus with slowly, gently, quietly and softly among the most frequent adverbs. Some examples from the corpus are included below:

Scratching across Alicia's hardened nipples, she dangled the whip in front of her and stroked gently with the soft leather.

Without warning, a soft whip beat a gentle rhythm on Alicia's back.

However roughly, quickly, hard, and harder suggest a tension between the assumed violence and aggressiveness of the sexual practices described and the ways they are apparently carried out. Some examples of rough* in the corpus are: 
She kissed me roughly, chewing on my lips and tongue, while grinding her pelvis against mine.

"Hey, easy, easy," she said laughing, as I got carried away and handled her tits too roughly.

She leaned over her and kissed her roughly, bruising Claire's lips, forcing her tongue between Claire's teeth, biting her neck

We also see verbs like graze, nuzzle, and caress. Touch (45 occurrences) is an important item and transitively collocates with pronouns her, your, you; intransitively with we or lips, indicating reciprocity. Slide occurs 45 times with her and a body part (hands or fingers, chiefly) positioned to the Right. The lesbians in our corpus share the sense of sex as work, but not with the same force as the gay male work: fingers and hands work their way in, and also body parts are worked (e.g. work her clit Table 4, line 14). Sweat in our corpus exists mostly as a noun (for Baker's gay males it is a verb) - it has body parts as subjects, and is linked to sensations - small, taste, feel. Another form of moisture is attributed to the vagina whose responsiveness is signalled by a large number of collocating adjectives: swollen, thrusting, tight, moist, pulsing, oozing, open, burning.

Sexual power is primarily invested in cunts which are far from passive - they throb and drip (Table 3, lines 2, 4 and 6) - and they collocate with other frequent body parts, for example with fingers both Left and Right, which go inside, in and into. Other things which are described as throbbing are pussy, mound and clitoris. By contrast lesbian cocks are relatively inactive, collocating in each instance with $m y$ and they are 
placed in the mouth which is the most frequent collocation to the Right. Mouths also search out other body parts, such as fingers, hand, tongue, breast, tit, cock, but significantly, not cunt.

[Table 3 here]

A clit is similarly autonomous and is represented as swollen, engorged, little, hungry, erected, sweet, hard, throbbing and quivering (some examples are included in Table 4). But this is often in response to having things done to it, for example, it gets sucked, stroked, tongued, fingered, and played with. There are also things pushed against her clit, presumably by an active (butch) narrator.

[Table 4 here]

Instead, it is fingers that appear to function phallically as they certainly do its work; they penetrate and collocate with wetness and cunt (Table 5, lines 8,11 ). There is an implied penetration by fingers which are often the object of a verb, with $I$, she or a proper noun as a subject (Table 5 , line 11 ).

[Table 5 here]

Clearly, various organs and appendages belonging to lesbians are both active, powerful, receptive, and pleasure-giving or -seeking. 
The lesbians in our stories appear less obsessed by orgasm than gay males in Baker's (2004a) and Bolton's (1995) studies, and it is not the orgasm of the narrator that matters, but rather, that generosity is bestowed on the narrator's sexual partner. There are 136 occurrences of come which signify orgasm collocating with she as subject to the Left and hard and before to the Right. In other words, there is a positive evaluation of the orgasm using the adverb 'hard' "she came hard". We find also that the power dynamic appears to be just as often inverted. For example, power collocates most frequently with her to the Left, while control occurs with you to the Left, as in the following examples:

Her power is now total

Now My Mistress begins using her strong hands to transfer her power and strength to my flesh.

"I know she is! I can feel her, I can feel her power."

She felt it as strongly as I felt her power.

Suddenly her power enveloped a new strength.

Due to my fresh welts, these moves were painful, and served to remind me of her power.

We both know that you are in complete control of every sensation - each moment of both pleasure and pain... 
In terms of lesbian gender, we offer that this is suggestive of a butch 'desire practice' (Munt, 1998). These stories clearly indicate to young butches what is expected of them. This supports the idea that the role of these stories is to liberate a fantasy, serve as an instruction manual or create a sense of community through shared knowledge and discourse. Our analysis suggests that most of the narrators in the stories assume a butch gender identity although it seems that both parties in the encounters are entitled to be active.

\section{Conclusion: A Lesbian Gender?}

What emerges from these texts are semantic themes revealed by the word frequency analysis which suggest a soft sado-masochistic orientation, modified by lexical appeals to gentleness which collocate with terms of affection. Through word frequency and collocational analysis, we encounter discourses of lesbians as powerful, sex-positive women and a proliferation of roles and sexual practices.

In our present analysis, in terms of gender and role relation, we find that the authors of these texts are constructing a particularly lesbian masculinity, which manifests as psychological power more often than physical aggression. Quite clearly our texts show how different patternings and distributions of masculinity, femininity, power and submission are manipulated to create a multitude of erotic dynamics for lesbians to explore. The genre of the texts permits the expression of an erotic dynamic; however, there is no evidence to suggest that the deployment of butch power replicates normative heterosexual social roles of oppression of the feminine. Our data shows how notions of butchness were still being contested in the $1990 \mathrm{~s}$, but more than anything else she is 
symbolic and, we argue, iconic. Jalas (2005: 57) writes about butch as a 'threshold effect' by which she means a visible representation which interrogates the boundaries of lesbian gender and authenticity. Our corpus analysis reveals that the butch narrators are constructed as active, powerful, but at the same time gentle, consensual. Patterns of collocations show that there is an eroticisation of the power dynamic, the essence of butchness. But her power is often reciprocated by the (femme) partner, and is also neutralised by the contradiction of soft gentle butches. Clearly, in these texts language acts to present butch and femme as psychological fantasy roles which allow exploration and appropriation, not merely a replication of heterosexual sexual patternings. Through the play of frequent words indicating gender signifiers, clothing, sex toys, actions, we also recognise a particular lesbian femininity and lesbian androgyny. In these texts we have the realisation of a proliferation of genders, and writing the tensions and interactions between them instantiates a unique discourse of the lesbian erotic. This deployment of specifically lesbian gender has the potential to disrupt hegemonic discourses. This makes the texts that comprise our corpus politically challenging and liberating. We chose to use stories written at this particular historical moment, as they seemed to draw on the identificatory and behavioral possibilities offered by emerging postmodern notions of the fluidity of gender. We recognise that these identifications, roles and lesbian genders may not persist beyond this moment. Future research might involve similar techniques of analysis applied to a broader range of lesbian erotic texts, defined in terms of production and audience.

These magazines provided a necessary, creative re-designation of language to cope with the inversions and complexities of lesbian gender and sexual practice. They evoke desire with a 'dissonant juxtaposition' of the performance of masculinity set 
against a female embodiment. Butler (1990: 123) offers the metaphor of 'figure to ground' to locate the inversions and transgressions which form the complex interplay of gendered desire. She sees the performance of masculinity within female embodiment as a highly transgressive act, the figure prominent against the ground of heterosexual coupling.

Within this genre, we feel that Butler's (1993) 'lesbian phallus' has been sought and realised. In its more concrete manifestations, we might suggest that both cunts and clits are responsive to the active, penetrative touch of fingers. This is revealed through the collocational analysis of these words. It is not without equivocation that the phallus finds itself redeployed as a figure of lesbian desire: 'What is unveiled is precisely the repudiated desire, that which is abjected by heterosexist logic and that which is defensively foreclosed through the effort to circumscribe a specifically feminine morphology for lesbianism' (1993: 86). It is a phallus which might well be found inadequate, or shameful, Butler contends, but at the same time it is a borrowing which deprivileges the phallus by 'removing it from the normative heterosexual exchange, and recirculating and reprivileging it between women' (1993: 88). We contend that the lesbian phallus does exist - she exists as representations of sexual power. But, of course, our analysis does not disturb the psychological representation of the phallus which is enjoyed, not abusively, but as erotic domination which is gentle and consensual in these texts.

It is apparent therefore that these lesbian authors have defined the discursive formation of a woman-centered erotic. The abundance of sexual roles and transgression of gender categories, as revealed through our corpus-based analysis, expands the range of identificatory possibilities for lesbians. No longer restricted to butch-femme roles 
made intelligible through the lens of heterosexual coupling, lesbians have finally arrived at Zita's (1990) 'lesbian authorship of 'self',

\section{References}

Ardill, S. and O'Sullivan, S. 1990. Butch/femme obsessions. Feminist Review 34. 79-85 Attorney General's Commission on Pornography. 1986. Final Report. Washington, D. C.: US Government Printing Office Baker P. 2004a. Public Discourses of Gay Men. London: Routledge Baker, P. 2004b. Corpus Linguistics and Sexuality: Text analysis workshop: The abc's of corpus linguistics : Methods, examples, pitfalls, and ways to avoid them. Paper presented at Lavender Languages and Linguistics XI Conference, American University, Washington, DC

Baker, P. 2004c. No effeminates please: A corpus-based analysis of masculinity via personal adverts in Gay News/Times, 1973-2000. Paper presented at Lavender Languages and Linguistics XI Conference, American University, Washington, DC Baker, P., Hardie, A. and McEnery, T. 2006. A Glossary of Corpus Linguistics. Edinburgh: Edinburgh University Press

Bolton, R. 1995. Sex talk: Bodies and behaviors in gay erotica. In W. Leap (ed) Beyond the Lavender Lexicon: Authenticity, Imagination, and Appropriation in Lesbian and Gay Languages. Amsterdam: Gordon and Breach. 173-206

Bright, D. 1998. The Passionate Camera: Photography and Bodies of Desire London: Routledge

Bright, S. 1990. Susie Sexpert's Lesbian Sex World. Pittsburgh: Cleis Press 
Bright, S. 1992. Susie Bright's Sexual Reality: A Virtual Sex World Reader. Pittsburgh: Cleis Press

Bright, S. 1995. Sexwise. Pittsburgh: Cleis Press

Butler, J. 1990. Gender Trouble: Feminism and the subversion of identity. New York:

Routledge

Butler, J. 1993. Bodies That Matter. New York: Routledge

Califia, P. 1986. The Obscene, Disgusting, and Vile Meese Commission Report.

Retrieved March 22, 2004, from http://eserver.org/cultronix/califia/meese/

Cossman, B., Bell, S., Gotell, L. and Ross, B. 1997. Bad Attitude on Trial:

pornography, Feminism and the Butler Decision. Toronto: University of Toronto Press

Dworkin, A. 1987. Intercourse. New York: The Free Press

Frye, M. 1990. Lesbian 'sex’. In J. Allen (ed) Lesbian Philosophies and Cultures.

Albany: SUNY Press. 305-315

Halberstam, J. 1998. Female Masculinity. Durham, N.C.: Duke University Press

Heywood, J. 1997. The object of desire is the object of contempt: Representations of masculinity in Straight to Hell magazine. In S. Johnson and U. Meinhof (eds) Language and Masculinity. Oxford: Blackwell. 188-207

Hunston, S. 2002. Corpora in Applied Linguistics. Cambridge: Cambridge University Press

Jacobs, G. 2000. Applying functional grammar: A discourse analysis of sexually explicit stories written in adult magazines. Social Semiotics 10 (3). 281-292 Jalas, K. 2005. Butch lesbians and desire. Women: A Cultural Review 16 (1). 52-72 Kennedy, G. 1998. An Introduction to Corpus Linguistics. London: Longman 
Lamos, C. 1994. The postmodern lesbian position: On Our Backs. In L. Doan (ed) The Lesbian Postmodern. New York: Columbia University Press. 85-103

Mackinnon, C. 1993. Only Words. Cambridge, MA: Harvard University Press Manning, E. 1997. Kissing and cuddling: The reciprocity of romantic and sexual activity. In K. Harvey and C. Shalom (eds) Language and Desire: Encoding Sex, Romance and Intimacy. London: Routledge. 43-59

McEnery, T. and Wilson, A. 1996. Corpus Linguistics: An Introduction. Edinburgh: Edinburgh University Press

Morrish, E. 1992. A referential space for the lesbian body. Phoebe: An Interdisciplinary Journal of Feminist Scholarship, Theory and Aesthetics 4 (2). 38-45

Munt, S. (ed) 1998. Butch Femme: Inside Lesbian Gender. London: Cassell

Rubin, G. 1992. Of catamites and kings: Reflections on butch, gender, and boundaries. In Nestle, J. (ed) The Persistent Desire: A Butch-Femme Reader. Boston, MA: Alyson. 46682

Scott, M. 1996. Wordsmith Tools. Oxford: Oxford University Press

Spender, D. 1980. Man Made Language. London: Routledge and Kegan Paul Stubbs, M. 1996. Text and Corpus Analysis. Oxford: Blackwell

Zita, J. 1990. Lesbian body journeys: desire making difference. In A. Jeffner (ed) Lesbian Philosophies and Cultures. Albany: SUNY Press. 327-346

\footnotetext{
${ }^{\mathrm{i}}$ Further analysis, including a keyword analysis, of this corpus can be found in Morrish, E. and Sauntson, H. 2007. New Perspectives on Language and Sexual Identity. Basingstoke: Palgrave.

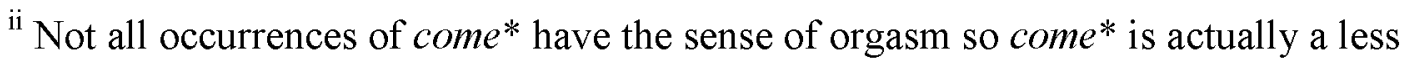
frequent verb of sexual activity than fuck* .
} 